\title{
ANALYTIC HIERARCHY PROCESS IN THE FUNCTION OF EVALUATION OF TRANSPORT SERVICE QUALITY IN BUS COMPANY
}

\author{
Tomislav Bubalo' ${ }^{1}$, Marijan Rajsman ${ }^{2}$, Pero Škorput ${ }^{3}$ \\ ${ }^{1,2,3}$ Faculty of Transport and Traffic Sciences, University of Zagreb, Croatia
}

Received 16 August 2020; accepted 9 October 2020

\begin{abstract}
Evaluating the competitiveness of bus operators is an important way of promoting the efficiency of transport and quality of transport services. Such evaluation is the scientific basis for decision-making related to the choice of transport company's development strategy in accordance with vision and set goals. The problem thus posed is the subject of research aimed at assessing the significance of some of the factors that depend on the competitiveness of business operations of bus operators. The problem is how to properly assess the importance of these factors, ie how to prioritize decisions that can lead to the choice of the best alternative for assessing the quality of transport services and improving the competitiveness of bus operators. The aim of the research is to present the possibility of applying multi-criteria analysis to the quality of transport services for the purpose of improving the business level of bus operators. The paper provides a formal definition of Analytic Hierarchy Process (AHP) multi-criteria analysis. The discovery of this study is finding effective ways to measure the quality of transport services so that companies could gain a competitive advantage in the market of transport services. The advantage and recommendation of the research results obtained in this way can also be used as input to another project or feasibility study, in which a much more complex decision must be made.
\end{abstract}

Keywords: Analytic Hierarchy Process (AHP), bus transport system, quality of transport service, evaluation, competitiveness.

\section{Introduction}

Given the market economy and the inevitable demand for profitability, an essential element of a successful transport business is the relationship of transport services offered by the transport company to the transport market in accordance with the state and trends of passenger transport demand and the optimization of the business system of carriers, primarily from the point of view of productivity and economy of business (Buble, 1997). It can therefore be said that effective competitiveness evaluation is an important way to promote the efficiency of the operation and quality of passenger transport systems. In this respect, successful management of transport processes is reflected in constant business decision-making related to the development of the transport process and the efficient and effective carrying out of transport (Lazibat, 2009).

The structure of road transport technology in road traffic is determined by the structure of the environment and the structure of

\footnotetext{
${ }^{1}$ Corresponding author: tomislav.bubalo@student.fpz.hr
} 
the traffic system in a certain space and a certain time. The structure of road transport technology in road traffic may also be other elements: natural, economic, security, management, and others (Županović, 1986). With regard to the optimization of passenger transport in road transport, the basic objective is to achieve such a level of transport service quality that is appropriate to the needs of the modern citizen, especially in terms of attractiveness and for those who own the car and still give priority to individual transport. Line intercity passenger transport can be defined as a subsystem in the system of passenger transport in road traffic, which compensates for passenger demand on pre-established lines, fixed tolls, and carriers tariffs under equal and preprescribed legal requirements for all types of transport service users (Rajsman, 2017). By joining the European Union, domestic carriers got strong competition on the European cargo market, requiring numerous qualitative adaptations and improvements not only for business improvement but also for survival on the market (Bubalo et al., 2015). Therefore, a constant evaluation of competitiveness and improvement of bus and coach transport services is essential. According to the data available from the Croatian Chamber of Commerce and the Croatian Chamber of Trades and Crafts, 2,395 road transport companies are registered in the Republic of Croatia, of which about $10 \%$ or 240 companies are registered for bus and coach transportation of domestic and international road transport (Bubalo et al., 2017).

The system of public road passenger transport and the level (level of satisfaction of its users) was a special subject of the EU Commission study at the Mobility Conference held in Paris in 2014. The research was conducted in cooperation with the International Association of Public Transport (UITP). The results of these studies show that EU residents are mostly satisfied with the public road transport service, as an exchange rate subsystem in the public transport system of passengers. The sample on which service satisfaction survey was conducted had 28,036 respondents. Different aspects of functioning and elements were studied in the public transport system of passengers. The following was established: in 23 out of $28 \mathrm{Member}$ States, at least $60 \%$ indicate "high" or "good" level of satisfaction with the quality of transport services. At the top of the satisfaction list, there are residents of Luxembourg ( $88 \%$ of respondents), Latvia $(83 \%)$ and Finland (82\%). At the bottom of the customer satisfaction level is Malta (31\%).

According to the quality of transport services, the level of satisfaction of service providers is as follows: frequency (69\%), passenger information (58\%), accuracy (58$70 \%)$, cleanliness of the passenger area (58$70 \%)$, safety (58-70\%), reliability (60-70\%), track adaptability (58-70\%), and service cost (39\%). UITP is the leader in the conception of sustainable mobility and brings together a world network of participants that provide public transport services. This organization has 1,500 members from 96 countries (UITP, 2018).

\section{Previous Research}

In the literature available, urban and suburban transport of passengers are primarily investigated and the quality of the products, not the services (especially the transport). This state of affairs opens up new possibilities for researching longdistance passenger transport in the road 
transport system and researching the quality of transport services in passenger traffic. It should be emphasized that very few works are modeling the quality management system for the transport of passengers to the micro transport of road transport companies in general and especially at the road transport companies (Jurčević et al., 2018). Below you will find specific titles describing the issues regarding to the quality of public road passenger transport.

The research (Zopounidis \& Doumpos, 2002) gives an assessment of the financial performance and sustainability of a transport company that carries out the evaluation by applying a multi-criteria analysis methodology based on the FINEVA (Financial Evaluation) multi-criteria system based on knowledge. The FINEVA system provides an assessment of the company's efficiency and sustainability, a combination of the expert system, the main component analysis method, and the UTASTAR multicriteria method (Utilites Adittives). The main criteria that affect the financial result of a carrier are the ratios of financial and industrial profitability as well as the current ratio that includes the company's liquidity. The results of this application show that the FINEVA system could provide the necessary tools to analyze the company's performance and sustainability, taking into account the preference and policy of the decision makers. In order to better understand the passenger's wishes and to gain their perception of the quality of transport services, (Barbino et al., 2012) the authors propose a hybrid approach based on the inconvenient AHP and fuzzy linguistic method for assessing the quality of transport services.

In the first phase, a hierarchy of SERVQUAL (Service Quality Index Quality System) was used. In the second stage, the AHP was used to analyze the structure of the service evaluation problem in the run. In the third stage, a sub-criterion was evaluated in order to qualitatively evaluate subjective attitudes of passengers. Research (Dell'Olio et al., 2010) assessing how users of public road transport see quality of service, solely on the basis of available information before and after driving. The application of this methodology can provide bus companies with valuable information for planning marketing policies targeted at different categories of users to improve service quality and attract more passengers in using public road transport.

In the paper (Guner, 2018), author propose a new approach to improving the quality of transport services by applying AHP in obtaining weight criteria and new methods in ranking TOPSIS (Technique for Order Preference by Similarity to Ideal Solution) where the conclusion was that courtesy, safety, and comfort were the highest ranked elements. The Quality of Service concept goes beyond the technical aspects of service delivery, encompassing the perception of passengers on what services should be and how services should be improved. The survey (Nassereddine \& Eskandari, 2017) assesses both criteria for identifying the most important elements of the quality of service for passengers and taking estimates of passengers based on these elements. A further exploration is an overview of new methods for improving the quality and efficiency of bus operators by applying an integrated approach GAHP analysis (Group Analytic Hierarchy Process) and multicriteria analysis of the set of alternatives used for ranking PROMETHEE (Preference Ranking Organization METHod for Enrichment Evaluations). 
In addition, the paper (Maha et al., 2014) presents new strategies to improve the quality of transport services and competitive public transport based on group research and surveys where they describe the application of fuzzy multi-criteria analysis in the assessment of the quality of transport services. The approach presented is computer-efficient, and fuzzy estimates expressed in language terms are often the most influential way for the decision maker to use in the evaluation process. In order to ensure an efficient service and maintain the success of a passenger transport business, the bodies responsible for organizing and managing companies regularly assess the success of bus companies according to certain criteria. Depending on the objectives of the evaluation problem, various criteria for assessing public transport can be used from the perspective of different stakeholders. For example, a bus company would focus more on operational performance criteria while passengers are more interested in criteria such as quality of service and transportation security.

The assessor may also have other criteria of his own interest, such as social sensitivity. In the paper (Ona et al., 2013), authors present a new approach to assessing the quality of transport services based on the SEM (Structural Equation Model) model used to detect latent aspects describing the service, and provide a theoretical description of the relationship between the aspects and the quality of the service. It is also interesting to study (Hensher et al., 2001) which provide an overview of the improvement of the quality of transport services in public road transport through the implementation of the SQI (Quality Index), model where comparisons of the efficiency of a bus carrier are based on known criteria and the level of quality of transport services. In a further review of literature paper (Hensher et al., 2010) presents a new model for assessing the quality of transport services using a GOC (Generalized Ordered Choice) model which takes into account preferential heterogeneity through immediate parameters in the expected variant of service quality choice.

In the paper (Chatterjee et al., 2018), authors propose a new approach to evaluate the environmental performance of suppliers for each evaluation criterion based on R'MAIRCA model (Rough Multi Attribute Ideal Real Comparative Analysis). Model implements a Spearman's rank correlation coefficient and other ranking methods. In the paper (Petrović \& Kankaraš, 2018) authors presents an approach in the determination and evaluation of the criteria and attributes of criteria for selecting the air traffic protection aircraft based on DEMATEL model (Decision Making Trial and Evaluation Laboratory Model). Research (Pamučar, Stević \& Zavadskas 2018) proposes an interval rough number enabled AHP-MABC model (Interval Rough Analytic Hierarchy Process - Multi Attributive Border Approximation Border Area Comparison) for web pages evaluation. Interval rough number is introduced to deal with the imprecisions in decision-making. The proposed model provides novel and more effective concept for alternative ranking. Multi-criteria techniques were compared based on interval rough and fuzzy approaches.

In the paper (Pamučar, Ćirović \& Sekulović, 2018) authors presents a research which is based on expert interviews, which is structured according to the principles of value-focused thinking and SWOT (Strengths, Weaknesses, Opportunities 
and Threats) analysis. They explain and present new hybrid FA'WOT model that combining the well know SWOT analysis and FAHP (Fuzzy Analytic Hierarchy Process) method. Research (Božanić et al., 2015) presents a modification of the AHP method, which takes into account the degree of uncertainty of the decision maker, that is, allows the decision maker with a certain degree of certainty (which is usually less than $100 \%)$ to define which linguistic expression corresponds to the comparison of optimality criteria. Paper (Popović et al., 2018) is based on the main difference between conceptual and theoretical frameworks as well as literature review of comparative studies of two multi-criteria decision making methods: Analytic Hierarchy Process (AHP) and Conjoint analysis.

\section{Methodology}

The Analytic Hierarchy Process (AHP) is among the most well-known and most-used methods for multi-criteria decision making in recent years. Basically, it is a hierarchical structure that is at the very top of the goal, at the first level is the criteria under the next level below sub-criteria, etc. At the lower level of the hierarchical structure there are alternatives. The AHP method uses datasheet data for comparing and ranking alternatives when deciding which alternative is in the advantage of the others. This method compares the advantages and disadvantages of certain alternatives and as a final one gives the priority of the alternative in the form of a single number. Criteria for choosing a particular alternative may have different importance, which is why they are given weight. The AHP method is based on comparing the alternatives in pairs. The weights of each criterion are determined by comparing the criteria in pairs and by determining how much more important the first criterion is than the second criterion.

The AHP method consist four basic steps (Kovačić, 2004):

1. Create hierarchy of top-down decisionmaking modeling hierarchy, criteria, and lower-level criteria, and alternatives at the bottom of the model;

2. At each level hierarchical structure in pairs compares the elements of that structure with each other, with the preferences of decision-makers expressed through the appropriate Saaty's scale of relevant importance;

3. From the assessment of the relative importance of the elements of the appropriate level of hierarchical structure of the problem using the appropriate mathematical problem, the local priorities (weights) of criteria, subcriteria, and alternatives are calculated, which are then synthesized in the overall alternative priorities;

4. Sensitivity analysis is performed.

The problem of performance assessment in the passenger transport sector usually includes a variety of organizations or business units $n$ (alternatives) $A_{i}(i=1,2, \ldots . n)$. These alternatives are evaluated on the basis of a set of $m$ criteria $C_{j}(j=1,2, \ldots, m)$, which are mutually independent. Each criterion $C_{j}$ can be divided into $p_{j}$ sub-criterion $C_{j k}(k=1,2$, ..., $p_{j}$ ) (Dimitrijević, 2017).

Linguistic terms are proposed intuitively and are simple to use in expressing subjectivity and estimation. In order to facilitate the production of qualitative estimates for the evaluation of selected alternative solutions, the linguistic terms defined in Table 1 are used. These linguistic terms are characterized by triangular numbers 
representing their approximate range of values between 1 and 9 , designated as $\left(a_{1}\right.$, $\left.a_{2}, a_{3}\right)$ where $1 \leq a_{1}, 1 \leq a_{2}, 1 \leq a_{3} \leq 9 . a_{2}$ is the greatest possible value of the language concept. Figure 1 demonstrates linguistic affiliation. Expressed in the linguistic terms defined in Table 1, the decision matrix for the criteria $m$ and $n$ alternatives is given as:

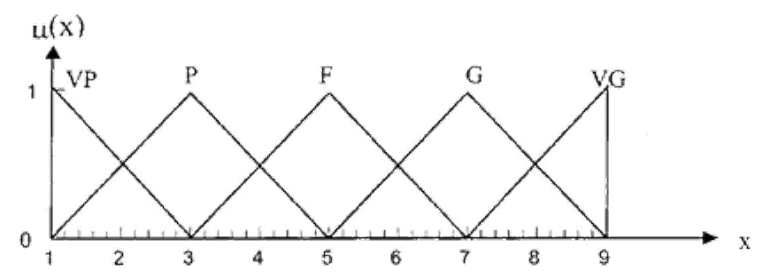

Fig. 1.

Functions of Membership of Language Terms Defined in Table 1

Table 1

Linguistic Terms used in the Decision Matrix

\begin{tabular}{|c|c|c|c|c|c|}
\hline Linguistic Term & $\begin{array}{c}\text { Very Poor } \\
(\mathrm{VP})\end{array}$ & Poor (P) & Fair (F) & Good (G) & $\begin{array}{c}\text { Very Good } \\
(\mathrm{VG})\end{array}$ \\
\hline $\begin{array}{c}\text { Membership } \\
\text { Function }\end{array}$ & $(1,1,3)$ & $(1,3,5)$ & $(3,5,7)$ & $(5,7,9)$ & $(7,9,9)$ \\
\hline
\end{tabular}

$$
X=\left[\begin{array}{llll}
\bar{x}_{11} & x_{12} & \ldots & x_{1 m} \\
x_{21} & x_{22} & \ldots & x_{2 m} \\
\ldots & \ldots & \ldots & \ldots \\
x_{n 1} & x_{n 2} & \ldots & x_{n m}
\end{array}\right]
$$

Where $X_{i j}$ represent the linguistic assessments of the performance rating of $A_{i}(i=1,2, \ldots$, $n)$ with respect to criterion $C_{j}(j=1,2 \ldots$, $m)$. The decision matrix is to be given by the decision makers or aggregated from the corresponding lower-level decision matrix.

If sub-criteria $C_{j k}\left(k=1,2, \ldots, p_{j}\right)$, are used for criterion $C_{j}$, a lower-level decision matrix is to be given as in (2) where $Y_{i k}$ are the linguistic assessments of the performance rating of alternative $A_{j}$ with respect to sub-criteria $C_{j k}$ of criterion $C_{j}$.

$$
y_{c j}=\left[\begin{array}{lllc}
y_{11} & y_{21} & \ldots & y_{n 1} \\
y_{12} & y_{22} & \ldots & y_{n 2} \\
\ldots & \ldots & \ldots & \ldots \\
y_{1 p j} & y_{2 p j} & \ldots & y_{n p j}
\end{array}\right]
$$

Matrix $X$ for the case of consistent estimates $a_{i j}=a_{i k}$ satisfies the equation:

$X n=n w$

Problem solving of weigths can be solved as a problem solving of equation:

$$
X w=\lambda w, \lambda \neq 0
$$

Matrix $X$ has properties for which only one of its inherent values is equal to $n$ and different from 0 . Since the sum of the eigenvalues of 
the positive matrix is equal to the trace of the matrix, or the sum of the diagonal elements, the null inherent value has the value $n$.

$\lambda_{\max }=n$

If the matrix $X$ contains inconsistent estimates (in practical examples it is almost always so) the vector weight $w$ can be obtained by solving the following equation system:

$$
\left(X-\lambda_{\max } I\right) w=0, \sum_{i} w_{i}=1
$$

Where $\lambda_{\max }$ is the largest inherent value of matrix $X$. Taking the above equations follows:

$$
\begin{aligned}
& X w=n w \\
& \sum_{j} a_{i j} w_{j}=n w \\
& \mathrm{w}=\frac{1}{n} \sum_{\mathrm{j}} a_{i j} w_{j}
\end{aligned}
$$

Where is:

$$
\begin{aligned}
& \Sigma_{\mathrm{i}} a_{i j}=\frac{w 1+w 2+\cdots+w n}{w j} \\
& W_{j}=\frac{w 1+w 2+\cdots+w n}{\Sigma a i j}
\end{aligned}
$$

From where follows the weight of an individual alternative $w_{i}$ :

$w_{i}=\frac{1}{n} \Sigma_{\mathrm{j}} \frac{a i j}{\sum a i j}$

Clearly, although the case of a two-level hierarchy is exemplied in this paper, the use of the normalized value function for aggregating assessments from lowerlevel sub-criteria can be applied to other performance evaluation problems involving multilevel criteria. The criteria for evaluating the quality of transport service were selected by the method of interviewing experts from the Faculty of Transportation and Traffic Sciences in Zagreb and experts from the road transport companies. An expert from the faculty organized a questionnaire on the basis of which they evaluated certain criteria and the quality of transport services. The examination of the quality of transport service was conducted on the basis of a point scale and ratings for each individual sub-criterion and criterion. The research was conducted on one international passenger line for five different bus carriers (alternatives). The next chapter presents a case study that compares the quality of transport services of the bus carrier Croatia Bus Ltd in relation to the quality of service of the other four bus carriers that were the subject of the study.

\section{Case Study - Bus Company from Zagreb}

The study was conducted of the quality evaluation of the bus company Croatia bus Ltd from Zagreb which provides the public transport service of passengers in the transport system of the Republic of Croatia. In order to ensure efficient service and maintain the success of a passenger transport business, the authorities responsible for traffic management in companies regularly assess the performance of a bus company according to certain criteria. For example, a bus company would focus more on quality related criteria. Travelers are more interested in criteria such as quality of service and safety. The 
evaluator may have other criteria of his own interest, such as social sensitivity. Through this comprehensive research and consulting with passenger transport administration, five criteria (safety, comfort, convenience, operations, and social duty) have been selected for assessing the success of a Croatian public passenger transport company. The hierarchical structure of the evaluation problem is presented in Figure 2 for every bus company (alternatives from A1 to A5). The sub-criterions that make up each of the five evaluation criteria and the corresponding results of the evaluation of bus companies are considered (Miller \& Kirby, 1984; Talley \& Becker, 1982).

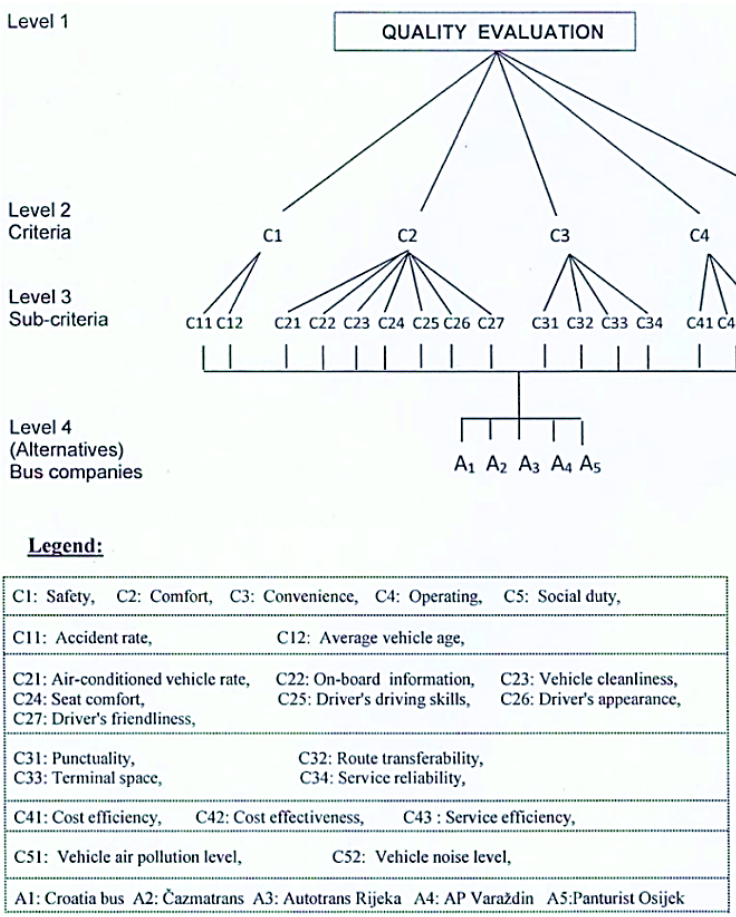

Fig. 2.

Hierarchical Structure for Quality Services Evaluation in bus Companies

1. Safety (C1) - Common indicators that can be used to measure safety levels include accident rate (total number of accidents per million miles by bus), average age of vehicle, average vehicle failure rate and traffic accident rate. Based on the availability of estimates and survey time, the two most important sub-criteria (accident rates and average vehicle age) are considered. Table 2 shows quantitative estimates of data and their corresponding results of linguistic estimation. The linguistic evaluation results were obtained by guiding decision makers through a subjective process of comparing the quantitative estimation data with the linguistic terms defined in Table 1. 
Table 2

Data of Quantitative Estimates and Corresponding Results of the Linguistic Assessment for the Security Criterion

\begin{tabular}{|c|c|c|c|c|c|}
\hline Safety (C1) & A1 & A2 & A3 & A4 & A5 \\
\hline \multirow{2}{*}{ Accident Rate (C11) } & 3.77 & 5.16 & 4.92 & 8.11 & 1.89 \\
\cline { 2 - 6 } & G & F & F & VP & VG \\
\hline \multirow{2}{*}{ Average Vehicle Age (C12) } & 12.14 & 5.52 & 8.15 & 7.67 & 9.45 \\
\cline { 2 - 6 } & VP & VG & VP & G & P \\
\hline
\end{tabular}

2. Comfort (C2) - The criterion of comfort refers to the level of service provided by the bus and the quality of the service the passenger experiences. The criteria to be considered include: air-conditioned cab, vehicle passenger information, vehicle cleanliness, seat comfort, driver's ability, driver's appearance, and driver's friendliness.
Some of these sub-criteria are quantitative and some are qualitative. Quantitative data is obtained from relevant companies for the transportation of passengers and government organizations. Qualitative data were obtained by examining the passengers directly using a structured questionnaire. Table 3 shows the linguistic estimate results.

Table 3

Results of Linguistic Estimates for Sub-criteria of Comfort Criteria

\begin{tabular}{|c|c|c|c|c|c|}
\hline Comfort (C2) & A1 & A2 & A3 & A4 & A5 \\
\hline Air-conditioned Vehicle Rate(C21) & P & F & VG & F & G \\
\hline On-board Information (C22) & VG & G & G & G & P \\
\hline Vehicle Cleanliness (C23) & F & F & F & F & P \\
\hline Seat Comfort (C24) & VG & F & VG & G & G \\
\hline Driver's Driving Skills (C25) & G & G & F & P & VG \\
\hline Driver's Appearance (C26) & F & G & VG & F & G \\
\hline Driver's Friendliness (C27) & P & VG & G & F & F \\
\hline
\end{tabular}

3. Convenience (C3) - the criterion of convenience is mainly related to the timeliness of bus services, the possibility of interconnection, terminal space, and reliability of the service. Table 4 shows the results of linguistic evaluation of criteria.

4. Operating (C4) - the cost efficiency, cost effectiveness, and service efficiency are widely used as performance indicators for assessing the operating performance of a transport company. These three indicators can be used to represent the services of the entrance, service outcomes, and consumption of public transport and operating business of the company. Efficiency measures reflect the use of resources, and effectiveness measures determine the degree to which the transport service meets the needs of passengers. In the case of bus operations, the cost efficiency, cost effectiveness, and service efficiency is measured by the total driving per kilometer of the vehicle per employee, the total number of passenger trips per employee, and the total number of passenger journeys per vehicle $/ \mathrm{km}$. 
Table 4

Linguistic Assessment Results for Sub-criteria of Convenience Criteria

\begin{tabular}{|c|c|c|c|c|c|}
\hline Convenience (C3) & A1 & A2 & A3 & A4 & A5 \\
\hline Punctuality (C31) & F & F & F & P & G \\
\hline Route Transferability (C32) & G & VP & P & G & F \\
\hline Terminal Space (C33) & VG & G & G & G & G \\
\hline Service Reliability(C34) & G & F & F & VG & F \\
\hline
\end{tabular}

Table 5

Data of Quantitative Estimates and Corresponding Linguistic Assessment Results for Operating Criteria

\begin{tabular}{|c|c|c|c|c|c|}
\hline Operating (C4) & A1 & A2 & A3 & A4 & A5 \\
\hline \multirow{2}{*}{ Cost Efficiency (C41) } & 1,678 & 2,039 & 3,118 & 2,377 & 2,894 \\
\cline { 2 - 6 } & $\mathrm{P}$ & $\mathrm{F}$ & $\mathrm{VG}$ & $\mathrm{G}$ & $\mathrm{VG}$ \\
\hline \multirow{2}{*}{ Cost Effectiveness (C42) } & 8,563 & 10,222 & 11,591 & 9,155 & 13,009 \\
\cline { 2 - 6 } & $\mathrm{VP}$ & $\mathrm{F}$ & $\mathrm{F}$ & $\mathrm{F}$ & $\mathrm{VG}$ \\
\hline \multirow{2}{*}{ Service Efficiency (C43) } & 4.60 & 4.77 & 4.13 & 3.96 & 4.75 \\
\cline { 2 - 6 } & $\mathrm{G}$ & $\mathrm{VG}$ & $\mathrm{F}$ & $\mathrm{P}$ & $\mathrm{VG}$ \\
\hline
\end{tabular}

5. Social duty (C5) - for convenience and simplicity, vehicle air pollution levels, and vehicle noise levels are used as subcriteria of social duty criteria. Table 6 shows the results of a linguistic assessment. The weighted five criteria vectors and their associated sub-criteria are given by the stakeholders who use the linguistic terms defined in Table 1. Table 6 shows the results of the estimation.

\section{Table 6}

Linguistic Assessment Results for Sub-criteria of Social Duty Criteria

\begin{tabular}{|c|c|c|c|c|c|}
\hline Social Duty (C5) & A1 & A2 & A3 & A4 & A5 \\
\hline Vehicle Air Pollution Level (C51) & P & G & F & G & G \\
\hline Vehicle Noise Level (C52) & F & P & F & F & F \\
\hline
\end{tabular}

\section{Analysis of Data in the Expert Choice Program}

An effective tool for resolving multicriteria decision-making is Expert Choice. This is a powerful performance analysis tool at the organization level. Expert Choice is a robust application designed for a desktop computer (PC), which enables teams to prioritize sorting alternatives, and making reliable decisions about alternatives to achieve the desired goals. This tool can integrate data from Microsoft Excel, Microsoft Project, and Oracle databases.
It is useful for scenarios in strategic budget planning and traffic projects. Expert Choice is fully applicable to the AHP method and supports all necessary steps. Enables multiple way problem structuring and comparison of alternatives and criteria in pairs in multiple ways, and also provides the ability to conduct and visualize sensitivity analysis based on a simple interactive method of weighting criteria and analysis (Aleksi \& Hocenski, 2009).

Figure 3 shows the target, criteria and alternatives in the ModelView window of 
Expert Choice. As an example, a model was designed to evaluate the quality service level of five bus operators (alternatives), the most important bus operator is Croatia Bus for whom a case study was conducted in this paper work. Criteria that are processed based on the data collected from the survey are: safety, comfort, convenience, operating, and social duty with the corresponding sub-criteria, which are also shown in the figure.

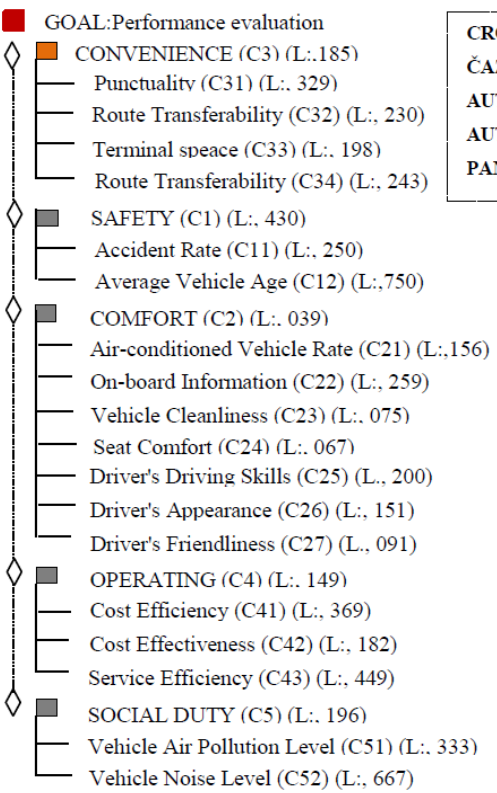

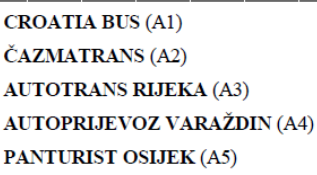

\section{Fig. 3.}

Goal, Criteria and Alternatives in the ModelView Window of Expert Choice

Once the criteria have been defined, it is necessary to determine their relevance to the alternatives. Criteria are compared in pairs with each other. After adding weight we calculate their local weight criteria. Figure 4 shows the procedure for comparison and weighting for the criterion of safety (C1) and convenience (C3).

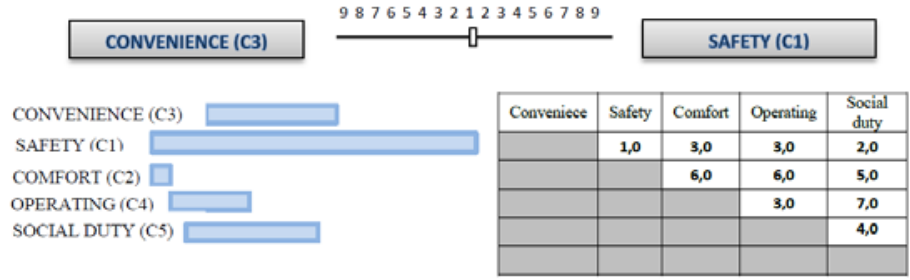

Fig. 4.

Parallel Couponing Procedure (PAIRWISE) and Adding Weight to the Criteria 
After assigning the weight to the criteria, it is necessary to add weights to all alternatives in relation to each criterion. Comparison is made with PAIRWISE by assigning weight alternatives for each criterion. Figure 5 shows the local priorities of the alternative and the weight of criteria.

\begin{tabular}{|c|c|c|c|c|c|c|c|c|c|}
\hline Ideal mode & PAIRWISE & PAIRWISE & PAIR WISE & PAIRWISE & PAIRWISE & PAIRWISE & PAIRWISE & PAIRWISE & PAIRWISE \\
\hline Alternative & Total & $\begin{array}{l}\text { Punctuality } \\
\text { (C31) (L: } \\
\text { 329) }\end{array}$ & $\begin{array}{l}\text { Route } \\
\text { Transferability } \\
\text { (C32) (L: } \\
\text { 230) }\end{array}$ & $\begin{array}{l}\text { Terminal } \\
\text { speace } \\
\text { (C33) (L: } \\
198)\end{array}$ & $\begin{array}{l}\text { Route } \\
\text { Transferability } \\
\text { (C34) (L:: } \\
\text { 243) }\end{array}$ & $\begin{array}{l}\text { Accident } \\
\text { Rate (C11) } \\
\text { (L: 2S0) }\end{array}$ & $\begin{array}{l}\text { Average } \\
\text { Vehicle } \\
\text { Age (C12) } \\
\text { (L:750) }\end{array}$ & $\begin{array}{l}\text { Air- } \\
\text { condationed } \\
\text { Vehicle } \\
\text { Rate (C21) } \\
(\mathrm{L}: 156)\end{array}$ & $\begin{array}{l}\text { On-board } \\
\text { Information } \\
(\mathrm{C} 22)(\mathrm{L}: \\
259)\end{array}$ \\
\hline $\begin{array}{l}\text { Croatia Bus } \\
\text { (A1) }\end{array}$ & 359 & 1.000 & 476 & 474 & 086 & 606 & 172 & 102 & 531 \\
\hline $\begin{array}{l}\text { Cazmatrans } \\
\text { (A2) }\end{array}$ & $\coprod^{526}$ & 348 & 305 & 1.000 & 295 & 769 & 227 & 133 & 517 \\
\hline $\begin{array}{l}\text { Autotrans } \\
\text { Rijeka (A3) }\end{array}$ & 706 & 484 & 195 & 303 & 300 & 453 & 1.000 & 1.000 & 633 \\
\hline $\begin{array}{l}\text { Autoprijevoz } \\
\text { Varażdin(A4) }\end{array}$ & 776 & 618 & 081 & 593 & 322 & 813 & 905 & 839 & 1.000 \\
\hline $\begin{array}{l}\text { Panturist } \\
\text { Osijek(A5) }\end{array}$ & 726 & 578 & 1.000 & 417 & 1.000 & 1.000 & 920 & 712 & 626 \\
\hline
\end{tabular}

Fig. 5.

Local Priority Alternatives

Figure 6a shows the overall alternative priorities after the synthesis carried out with respect to the presented goal and a specific criterion and sub-criterion, while Figure
$6 \mathrm{~b}$ shows data analysis for all sub-criteria relevant to the evaluation of service quality in company Croatia bus.

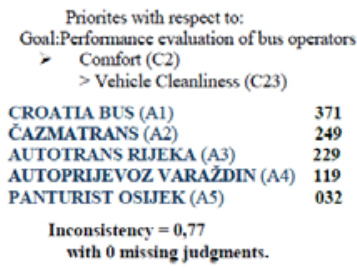

Fig. 6a.

Total Priority Alternative
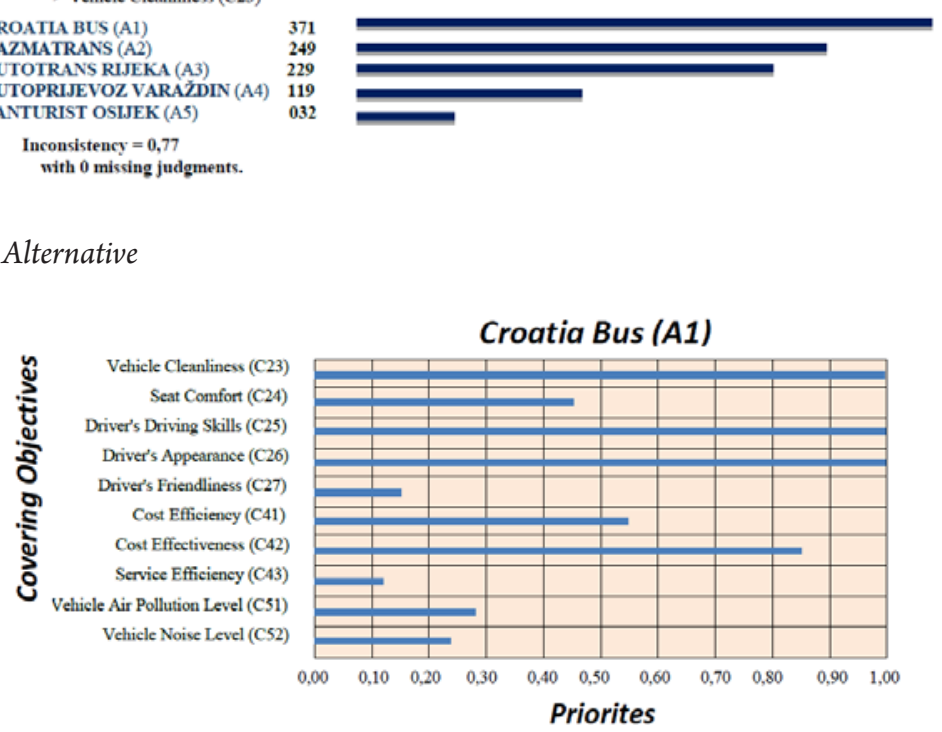

Fig. 6b.

Analysis of Sub-criteria for Company Croatia Bus 
After determining criteria and defining alternatives, and setting all the required weights, it is possible to make comparative analysis of alternatives, criteria or sub-criteria.
Figure 7 shows a comparative analysis of the two alternatives: for example Croatia bus (A1) and Čazmatrans (A2), where the value of the criteria between alternatives is visible.

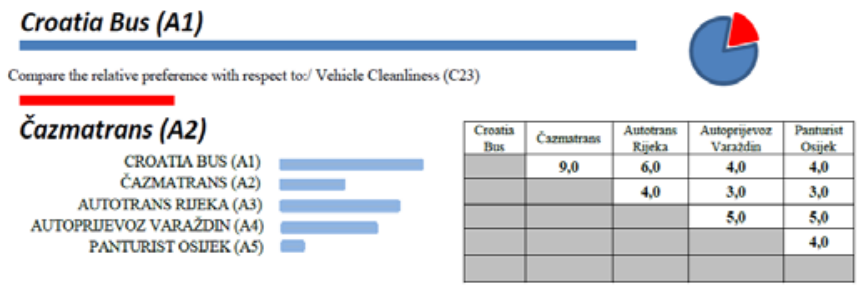

Fig. 7.

Comparative Analysis of Alternatives to Sub-criteria Cleanliness of Vehicles (C23)

Figure 8 shows the overall performance bus averages the worst value of business estimate for all carriers, where according performance in comparison with other to survey results, the company Croatia passenger transport companies.

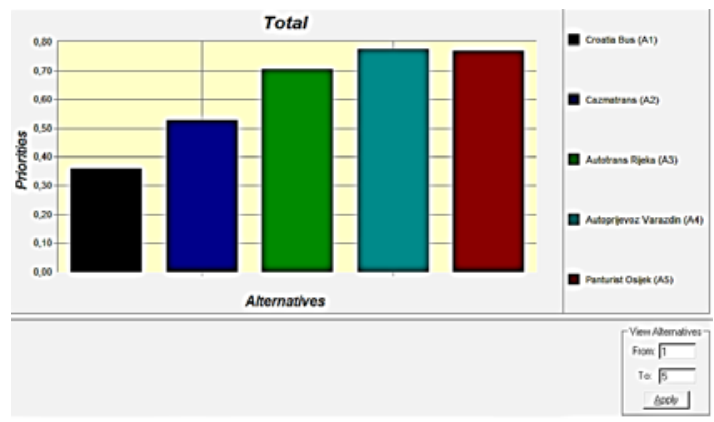

Fig. 8.

Results of the Assessment of the Quality Service of Bus Operators

Figure 9 shows the so-called Performance graphical representation of the impact of individual criteria on alternatives. It reflects the effects of particular criteria weights on the current and overall ranking of alternatives. The current ranking of alternatives represents the change in priority of an alternative influenced by the weight of one criterion, and the overall ranking of alternatives represents the ranking of alternatives influenced by the weight of all criteria. The diagram shows that the Croatia Bus alternative is positively affected by the comfort criterion, while the safety and sustainability criteria negatively effect on the alternative. 


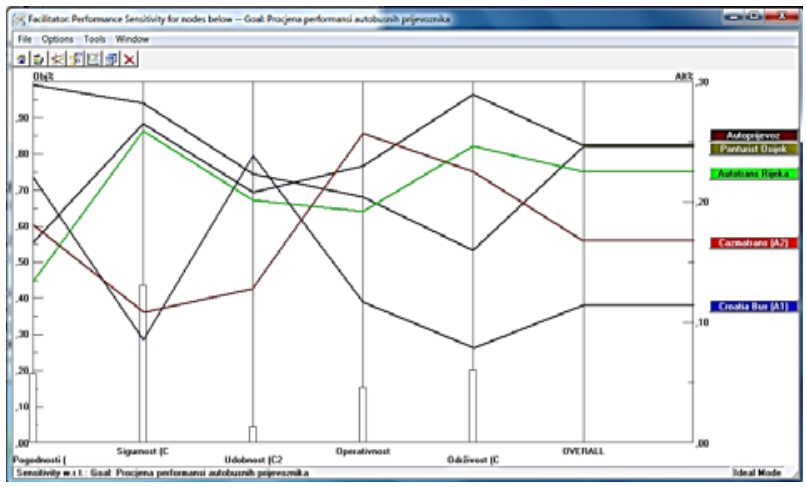

Fig. 9.

Sensitivity Analysis of the Quality Service of Bus Operators

\section{Conclusion}

Multi-criteria decision making in practice is an extremely complex process with a variety of applications in all areas of human activity. In this research, it is presented that the use of this methodological approach can effectively measure the quality of transport services

in road passenger transport. Data can be collected and valorised for each criterion and sub-criterion of the quality of transport service for an individual bus carrier as shown in Chapter 4. With the data thus collected, an evaluation of the overall quality of the transport service can be performed for each individual carrier as shown in Chapter 5 . A systematic analysis of the collected data determined in the sensitivity analysis that the best overall quality of transport service in terms of criteria and sub-criteria is provided by Autoprijevoz Varaždin (A4), then Panturist Osijek (A5), while convincingly the worst quality of transport service is provided by Croatia Bus (A1). It should also be noted that the satisfaction of evaluator is a dynamic parameter of a business organization (bus company). Future changes in the passenger bus market may affect the wishes and expectations of evaluators. For example, some dimensions of satisfaction may become critical in the near future if evaluators give more importance to them.

Using high quality computer programs, evaluation of service quality can be determined relatively quickly with a high degree of reliability, but nevertheless it is necessary to carry out a detailed analysis in order to understand the impact of each criterion or condition considered in its adoption. Thus, their impact analysis gets even weightier and multi criteria decision making is an additional incentive for even more extensive theoretical considerations, creating new and improving already existing methods, and even closer interaction with professionals to create the most sophisticated interactive computer programs based on these methods. Also, this approach opens up further research on this issue and possible further extension of the number of organizational factors that are of importance to quality. Once the necessary organizational preconditions have been realized, it is possible to realize the transport service through the principle of applying the principle of business excellence. 


\section{References}

Aleksi, I.; Hocenski, Z. 2009. Application of Expert Choice Tool and AHP-Elaborate. Faculty of Electrical Engineering, University in Osijek, Croatia. 12 p.

Barbino, B.; Deiana, E.; Tilocca, P. 2012. Measuring service quality in urban bus transport: a modified SERVQUAL approach, International Journal of Quality and Service Sciences 4(3): 238-252.

Božanić, D.; Pamučar, D.; Bojanić, D. 2015. Modification of the analytic hierarchy processes (AHP) method using fuzzy logic: Fuzzy AHP approach as a support to the decision making process concerning engagement of the group for additional hindering, Serbian Journal of Management 10(2): 151-171.

Bubalo, T.; Vojvodić, H.; Bokulić, D. 2015. The exchange of data in the intercity bus traffic. In Proceedings of the $23^{\text {rd }}$ Telecommunications Forum, TELFOR, Belgrade, Serbia.

Bubalo, T.; Jurčević, M.; Steiner, S. 2017. Analysis and Strategic Planning of Bus Passenger Transport with Reference to the Status of Croatia. In Proceedings of the $25^{\text {th }}$ International Symposium on Electronics in Transport ISEP, Ljubljana, Slovenia. ISBN:978-961-6187-67-1.

Buble, M. 1997. Strategic Management. Scientific book, Faculty of Economics, University in Split, Croatia. 13$18 \mathrm{p}$.

Chatterjee, K.; Pamučar, D.; Zavadskas, E. 2018. Evaluating the performance of suppliers based on using the R'AMATEL-MAIRCA method for green supply chain implementation in electronics industry, Journal of Cleaner Production 184(1): 101-129.

Dell'Olio, L.; Ibeas, A.; Cecin, P. 2010. Modelling user perception of bus transit quality, Transport Policy 17(6): 388-397.
Dimitrijević, B. 2017. Multi Decision Making in Traffic and Transportation. Scientific book, Faculty of Traffic and Transportation Engineering, University in Belgrade, Serbia. 25-27 p.

Guner, S. 2018. Measuring the quality of public transportation systems and ranking the bus transit routes using multi-criteria decision making techniques, Case Studies on Transport Policy 6(2): 214-224.

Hensher, D.: Stopher, P.; Bullock, P. 2001. Developing a service quality index (SQI) in the provision of commercial bus contracts, Journal of Public Transportation 3(1): 52-65.

Hensher, D.; Mulley, C.; Yahya, N. 2010. Passenger experience with quality bus service: the tyne and wear "superoute“ services, Transportation 37(2): 239-256.

Jurčević, M.; Bubalo, T.; Mandžuka, B. 2018. Influence of Costs on the Optimization of Transport Routes (Case Study)-Passenger Transportation Company from Zagreb, Journal Econviews 31(1): 65-73.

Kovačić, B. 2004. Multiple Decision Making in Traffic. Master's Degree paper work, Faculty of Transportation and Traffic Sciences, University in Zagreb, Croatia. $23 \mathrm{p}$.

Lazibat, T. 2009. Quality Management. Scientific book, University in Zagreb, Croatia. 11-16 p.

Maha, A.; Bobalca, C.; Tugulea, O. 2014. Strategies for the Improvements in the Quality and Efficiency of Public Transportation, Procedia Economics and Finance 15(1): 877-885.

Miller, G.K.; Kirby, R.F. 1984. A structured approach to monitoring and evaluating public transportation services, Transportation Quarterly 38(1): 23-46. 
Nassereddine, M.; Eskandari, H. 2017. An integrated MCDM approach to evaluate public transportation systems in Tehran, Transportation Research Part A: Policy and Practice 106: 427-439.

Ona,J.; Ona, R.; Eboli, L.; Mazzulla, G. 2013. Perceived service quality in bus transit service: a structural equation approach, Transport Policy 29(1): 219-226.

Pamučar, D.; Stević, Ž.; Zavadskas, E. 2018. Integration of interval rough AHP and interval rough MABAC methods for evaluating university web pages, Applied Soft Computing 67(2): 141-163.

Pamučar, D.; Ćirović, G.; Sekulović, D. 2018. Development of an integrated transport system in distribution centres: a FA'WOT analysis, Technical Gazzete 22(3): 649-658.

Petrović, I.; Kankaraš, M. 2018. DEMATEL-AHP multi-criteria decision making model for the selection and evaluation of criteria for selecting an aircraft for the protection of air traffic, Decision Making: Applications in Management and Engineering 1(2): 93-110.

Popović, M.; Kuzmanović, M.; Savić, G. 2018. A comparative empirical study of Analytic Hierarchy Process and Conjoint analysis: Literature review, Decision Making: Applications in Management and Engineering 1(2): 153-163.
Rajsman, M. 2017. Technology of Passengers Transportation in Road Traffic. Scientific book, Faculty of Transportation and Traffic Sciences, University in Zagreb, Croatia. 31 p.

Talley, W.K.; Becker, A.J. 1982. A single measure for evaluating public transit systems, Transportation Quarterly 36(3): 423-431.

UITP. 2018. International Association of Public Transport UITP. Available from Internet: < $\underline{\text { http: } / /}$ www.uitp.org/>. [Accessed: May 2018].

Zopounidis, C.; Doumpos, M. 2002. Multi-criteria Decision Aid in Financial Decision Making: Methodologies and Literature Review, Journal MultiCrit.Decis. Anal. 11(1): 167-186.

Županović, I. 1986. Road Traffic Technology. Scientific book, Faculty of Transportation and Traffic Sciences, University in Zagreb, Croatia. 6-9 p. 